\title{
Targeting multidrug resistance in cancer by natural chemosensitizers
}

\author{
Ahmed R. Hamed ${ }^{1,2^{*}}$ D, Nahla S. Abdel-Azim¹ ${ }^{1}$ Khaled A. Shams ${ }^{1}$ and Faiza M. Hammouda ${ }^{1}$
}

\begin{abstract}
Background: Statistics on cancer incidence and mortalities indicate that this disease still has a fatal outcome for a majority of patients due to non-sufficient treatment. The options available for cancer treatment include chemotherapy, which still commands a leading position in clinical oncology.

A major obstacle to successful chemotherapy is the development of cellular resistance to multiple structurally unrelated anticancer drugs. This phenomenon has been termed multidrug resistance (MDR), which occurs in a majority of cancer patients. MDR is mainly due to the overexpression of $A B C$ transporters which extrude chemotherapeutic drugs outside of cancer cells. A plethora of synthetic chemosensitizers have been described during the past decades that block ABC transporter function to reverse their MDR. However, none of them reached clinical routine application as of yet. In this review, we highlight the potential of natural products derived from plants, marine organisms, fungi, and other sources as chemosensitizers to the targeted major $A B C$ transporters ( $A B C B 1, A B C C 1$, and $A B C G 2)$.

Conclusion: Natural compounds may serve as lead compounds for the development of novel $A B C$ transporter inhibitors with improved pharmacological features that can be used as adjuvant therapy to enhance the efficacy of chemotherapeutic drugs against MDR.
\end{abstract}

Keywords: Cancer, Multidrug resistance, Chemotherapy, Chemosensitizers, P-glycoprotein

\section{Introduction}

Cancer includes a group of diseases that are characterized by abnormal and out of control spreadable cellular growth (Mbaveng et al. 2017). Causative agents of cancers are either external such as tobacco consumption and infections; or internal such as immune conditions, genetic mutations, and hormonal imbalance. The incidence of cancer is not limited to developing countries but also to already developed ones and the burden of cancer affects both. According to the World Health Organization (WHO), malignant neoplasms are ranked the second leading cause of deaths worldwide after cardiovascular diseases. In 2012 alone, a global record of 14.1 million newly diagnosed cancer cases with 8.2 million deaths due to cancer were reported (Torre et al. 2015). Moreover, these estimates are expected to increase by 2030 to about $150 \%$ which constitute a ringing

\footnotetext{
* Correspondence: n1 ragab2004@yahoo.com

${ }^{1}$ Chemistry of Medicinal Plants Department, National Research Centre, 33

El-Bohouth St., Dokki, Giza 12622, Egypt

${ }^{2}$ Biology Unit, Central Laboratory for Pharmaceutical and Drug Industries Research Division, National Research Centre, 33 El-Bohouth St., Dokki, Giza 12622, Egypt
}

alarm. These statistical estimates are based on GLOBOCAN 2012 presented by the International Agency for Research on Cancer (IARC) (Torre et al. 2015; Society A.C 2016).

Although the general term cancer covers many different diseases, most types of cancers share a common feature of not acting to available chemotherapies through development of multidrug resistance (MDR). MDR is a phenomenon by which cancer cells develop broad resistance to a wide variety of structurally and functionally unrelated compounds which may arise from several mechanisms of which the best described is the overexpression of drug efflux proteins such as P-glycoprotein. This ultimately leads to cancer relapse and death in $90 \%$ of patients. Some cancers such as gastrointestinal and renal cancers are largely unresponsive to chemotherapy, i.e., they have a high degree of intrinsic MDR, whereas leukemias, lymphomas, ovarian, and breast cancers often respond to initial treatment, but then acquire MDR during the course of the disease. MDR to anticancer drugs is therefore a serious health problem that dramatically affects the efficacy of cancer treatments. 
In this article, we review the possible mechanisms of multidrug resistance with focus on efflux transportersrelated MDR. We also emphasize how natural products constitute a promising value as chemosensitizers through inhibition of different efflux proteins.

\section{Mechanisms of drug resistance in cancer}

The cancer treatments available to patients include chemotherapy, radiotherapy, surgery, immunotherapy, or a combination of them (Gottesman et al. 2002; Saeed et al. 2016; Saluja et al. 2016; Nie et al. 2016). Although many cancer types are curable with chemotherapeutic cytotoxic agents, sometimes chemoresistance against cancer therapeutic agents develops. Chemoresistance against drugs can be either "intrinsic" which describe the pre-existing constitutive overexpression of cancer cell detoxification system before the start of chemotherapeutic regimen, or "acquired" where it develops after the start of the chemotherapy over time or after a secondary chemotherapy with tumor relapse (Gottesman 2002; Quintieri et al. 2007). The mechanisms through which cancer chemotherapy fails include pharmacological, physiological, and/or cellular mechanisms (Sikic 2015). First, the pharmacological mechanisms of chemotherapy failure may include insufficient drug dosing, or suboptimal dosing regimens of the chemotherapeutic regimens (Sikic 2015; Marangolo et al. 2006; Carlson and Sikic 1983).

Second, the physiological mechanisms of chemotherapy failure, however, include lack of optimal distribution of the chemotherapeutic agents to what is called "sanctuary sites" due to the presence of the blood-brain barrier (at the central nervous system) and blood-testicular barrier (at testes) (Fromm 2004).

Another physiological mechanism for the chemotherapy failure is the poor distribution of the chemotherapeutic agent to cancer tissue due to the poor vasculature in angiogenesis process (Kyle et al. 2007). Therefore, the use of anti-angiogenic agents (e.g., sunitinib) helped patients to revert vasculature back to normal and improved the distribution of chemotherapeutic drug to their target cancer tissues (Matsumoto et al. 2011).

Third, the cellular mechanisms involved in the chemotherapy resistance and eventually failure are schematically outlined in Fig. 1.

\section{Multi-drug resistance: a specific type of resistance}

A specific form of cellular drug resistance in cancer is termed multi-drug resistance (MDR).This is a phenomenon by which cancer cells become cross-resistant to a wide variety of structurally and pharmacologically unrelated cancer cytotoxic drugs such as vinblastine, paclitaxel, and doxorubicin (Callies et al. 2016; Wu et al. 2014; Kuete and Efferth 2015; Eichhorn and Efferth 2012). MDR renders the tumor cells non-responsive to treatment and failure of chemotherapy in 90\% of metastatic cancers (Bernardes de Andrade Carli et al. 2013; Turk et al. 2009; Longley et al. 2006).

The main mechanism describing MDR in cancer is the overexpression of ATP binding cassette $(\mathrm{ABC})$ transporter proteins that effectively efflux diverse chemotherapeutic agents outside the cancer cells, decreasing the intracellular drug concentration, rendering chemotherapy ineffective

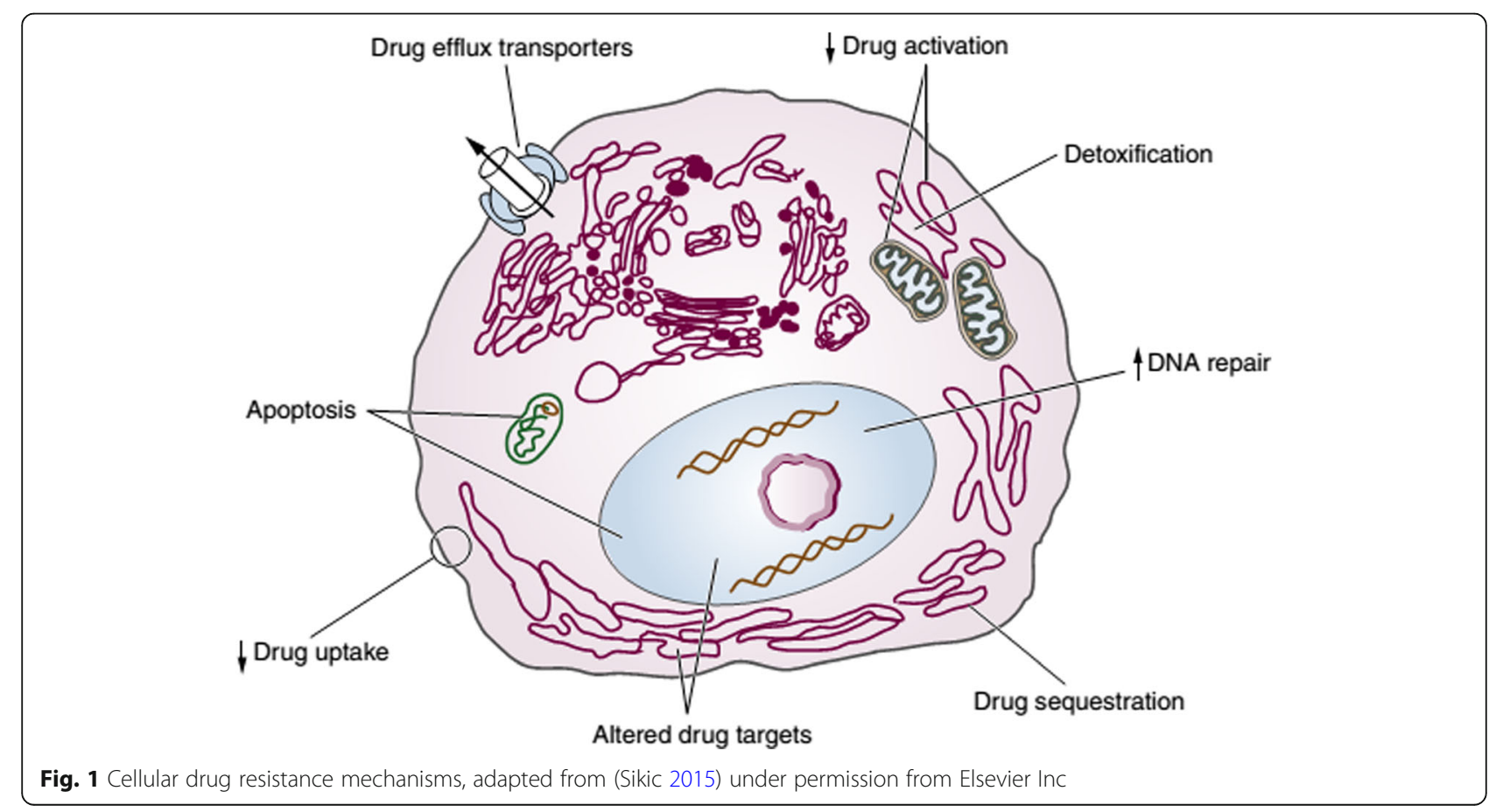


(Fig. 2) (Saraswathy and Gong 2013; Yan et al. 2014; Krishna and Mayer 2000; Gillet et al. 2007; Kadioglu et al. 2016).

ABC transporters in normal physiology and cancer There are $49 \mathrm{ABC}$ transporter genes in the human genome (Huang 2007; Gottesman and Ambudkar 2001; Glavinas et al. 2004). In normal physiology, these transporters actively transport endogenous and exogenous substrates through biological membranes into body tissues, such as small intestine, colon, kidney, pancreas, blood-brain barrier, and blood-testes barrier by ATP hydrolysis (Fromm 2004; Abdallah et al. 2015). In addition to the detoxification of xenobiotics, efflux transporters have a role in mediating the transport of some substrates across the cellular membranes such as cholesterol, amino acids, sugars, lipids, peptides, hydrophobic drugs, and antibiotics (Gottesman and Ambudkar 2001; Dean and Annilo 2005; Ifergan et al. 2004; Shi et al. 2007a; Shi et al. 2007b). However, in cancer cells, some of these transporters are responsible for chemotherapy failure.

The identified human drug transporter protein superfamily is divided into seven sub-families: namely $A B C A$, $\mathrm{ABCB}, \mathrm{ABCC}, \mathrm{ABCD}, \mathrm{ABCE}, \mathrm{ABCF}$, and $\mathrm{ABCG}$ (Kathawala et al. n.d.) with diverse physiological functions and roles in multidrug resistance (Table 1).

\section{Actîne A:C transporter \\ [HRRcels]}

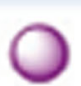

Efiilux

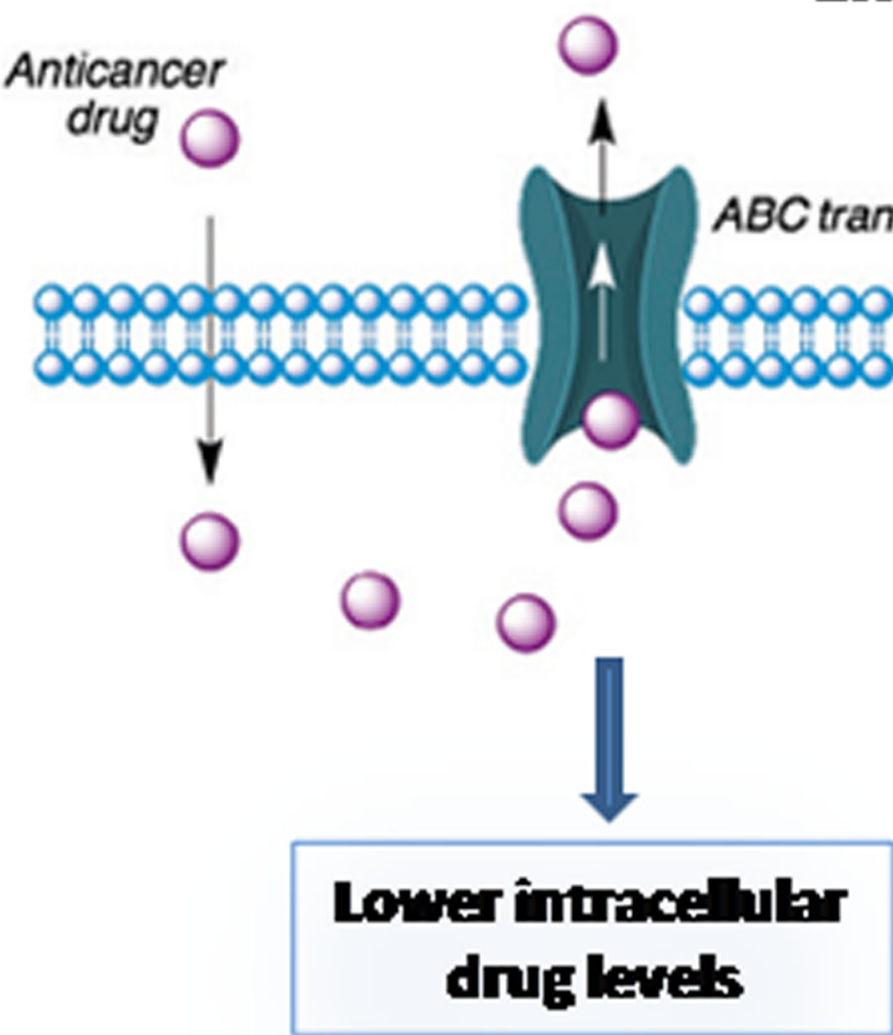

Fig. 2 Schematic representation of MDR in cancer cells with ABC transporter-mediated drug efflux. Adapted from (Avendaño and Menéndez 2015) under permission from Elsevier Inc 
Table 1 Families of human ABC transporters and their functions. Data were adapted from Vasiliou et al. (2009)

\begin{tabular}{|c|c|c|}
\hline ABC transporter family & $\mathrm{ABC}$ transporter & Major function \\
\hline \multirow[t]{12}{*}{$A B C A$} & $\mathrm{ABCA} 1$ & Efflux of cholesterol \\
\hline & $\mathrm{ABCA} 2$ & MDR \\
\hline & $A B C A 3$ & \\
\hline & $\mathrm{ABCA} 4$ & Efflux of N-retinylidene-phosphatidylethanolamine (PE) \\
\hline & ABCA5 & Urinary diagnostic marker for prostatic intraepithelial neoplasia (PIN) \\
\hline & ABCA6 & MDR \\
\hline & ABCA7 & Efflux of Cholesterol \\
\hline & $\mathrm{ABCA8}$ & Transports of some lipophilic drugs \\
\hline & ABCA9 & Might play a role in monocyte differentiation and macrophage lipid homeostasis \\
\hline & $\mathrm{ABCA} 10$ & Cholesterol-responsive gene \\
\hline & $\mathrm{ABCA} 12$ & Has implications for prenatal diagnosis \\
\hline & $\mathrm{ABCA} 13$ & Inherited disorder affecting the pancreas \\
\hline \multirow[t]{11}{*}{$A B C B$} & $A B C B 1$ & MDR \\
\hline & ABCB2-TAP1 & Peptide transport \\
\hline & ABCB3-TAP2 & Peptide transport \\
\hline & ABCB4 & Phosphatidylcholine (PC) transport \\
\hline & ABCB5 & Melanogenesis \\
\hline & ABCB6 & Iron transport \\
\hline & $\mathrm{ABCB7}$ & $\mathrm{Fe} / \mathrm{S}$ cluster transport \\
\hline & ABCB8 & Intracellular peptide trafficking across membranes \\
\hline & ABCB9 & Located in lysosomes \\
\hline & ABCB10 & Export of peptides derived from proteolysis of inner-membrane proteins \\
\hline & ABCB11 & Bile salt transport \\
\hline \multirow[t]{13}{*}{$A B C C$} & $\mathrm{ABCC} 1$ & MDR \\
\hline & $\mathrm{ABCC} 2$ & Organic anion efflux \\
\hline & $\mathrm{ABCC} 3$ & MDR \\
\hline & $\mathrm{ABCC} 4$ & Nucleoside transport \\
\hline & ABCC5 & Nucleoside transport \\
\hline & ABCC6 & Expressed primarily in liver and kidney \\
\hline & ABCC7-CFTR & Chloride ion channel (same as CFTR gene in cystic fibrosis) \\
\hline & $\mathrm{ABCC} 8$ & Sulfonylurea receptor \\
\hline & ABCC9 & Encodes the regulatory SUR2A subunit of the cardiac K(ATP)channel \\
\hline & $\mathrm{ABCC} 10$ & MDR, xenobiotic efflux \\
\hline & $\mathrm{ABCC} 11$ & \\
\hline & $\mathrm{ABCC} 12$ & \\
\hline & $\mathrm{ABCC} 13$ & Encodes a polypeptide of unknown function \\
\hline \multirow[t]{4}{*}{$\mathrm{ABCD}$} & $A B C D 1$ & Transport of Very long chain fatty acid (VLCFA) \\
\hline & $\mathrm{ABCD} 2$ & Major modifier locus for clinical diversity in X linked ALD (X-ALD) \\
\hline & ABCD3 & Involved in import of fatty acids and/or fatty acyl coenzyme as into the peroxisome \\
\hline & ABCD4 & May modify the ALD phenotype \\
\hline ABCE & ABCE1 & Oligoadenylate-binding protein \\
\hline \multirow[t]{3}{*}{$A B C F$} & ABCF1 & Susceptibility to autoimmune pancreatitis \\
\hline & ABCF2 & Tumor suppression at metastatic sites and in endocrine pathway for breast cancer/drug resistance \\
\hline & ABCF3 & Also present in promastigotes (one of five forms in the life cycle of trypanosomes) \\
\hline
\end{tabular}


Table 1 Families of human ABC transporters and their functions. Data were adapted from Vasiliou et al. (2009) (Continued)

\begin{tabular}{lll}
\hline ABC transporter family & ABC transporter & Major function \\
\hline$A B C G$ & $A B C G 1$ & Cholesterol transport \\
& $A B C G 2$ & MDR, xenobiotic efflux \\
& $A B C G 4$ & Found in macrophage, eye, brain and spleen \\
& $A B C G 5$ & Sterol transport \\
& ABCG8 & Sterol transport \\
\hline
\end{tabular}

\section{Major ABC transporters involved in MDR of cancer}

The assembly of different $A B C$ efflux transporters across cell membrane is similar. It is composed of transmembrane domains (TMDs) each contains a number of membrane-spanning $\alpha$-helices $(5-10$ helices $)$ and nucleotide-binding domains (NBDs). The TMD is the site where the substrate binds to the transporter, whereas NBD exerts ATPase activity that hydrolyses ATP molecules to provide the energy required for the substrate (drug) efflux process against concentration gradients to extracellular space (Avendaño and Menéndez 2015; Gottesman and Ling 2006; Yu et al. 2016). ABC transporters appear as full transporters or half transporters that dimerize to form functional full transporter units.
Three efflux transporters have been investigated in much more detail concerning their role for MDR in cancer cells: ABCB1 (also termed P-glycoprotein, P-gp, or MDR1), ABCC1 (also termed MDR-associated protein 1 or MRP1), and ABCG2 (also termed breast cancer resistance protein $\mathrm{BCRP}$ or mitoxantrone resistance protein MXR) (Fig. 3).

\section{ABCB1 (P-gp, MDR1)}

$A B C B 1$ was the first efflux protein to be identified in MDR Chinese hamster ovary cells $(\mathrm{CHO})$ by Juliano and Ling in 1976 (Juliano and Ling 1976). It is a $170 \mathrm{kDa}$ glycoprotein that is expressed in liver, placenta, kidney, intestine- and blood-brain barriers, where it has detoxification and transport physiological functions. $\mathrm{ABCB} 1$ is

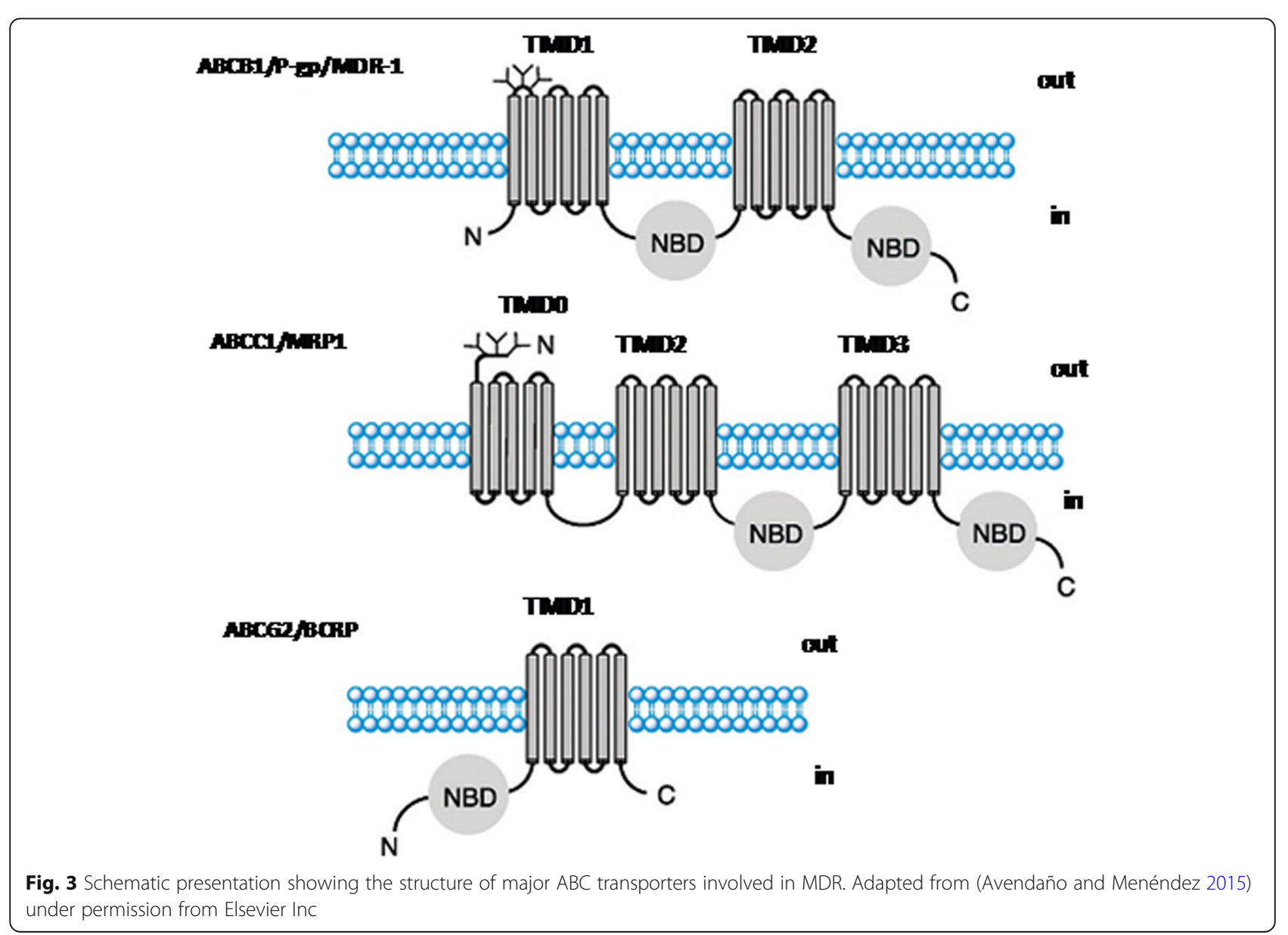


the most extensively studied efflux transporter and accounts for the efflux of about half the number of anticancer drugs used in clinic (Avendaño and Menéndez 2015). In cancer cells, the overexpression of ABCB1 confers MDR phenotype to cells against diverse traditional chemotherapeutic drugs of unrelated chemical structures and variable mechanisms of actions such as paclitaxel, doxorobicin, and vinblastine and many others (Loo and Clarke 2005). In addition, the ABCB1 transporter also mediates the efflux of the marine antileukemia drug imatinib (Avendaño and Menéndez 2015).

The human ABCB1 protein contains 1280 amino acid residues forming 2 similar halves. Each half contains one TMD with six $\alpha$-helices (TMD1 and TMD2) and a hydrophilic NBD (NBD1 and NBD2) (Fig. 3). The binding of ABCB1 drug substrates to the TMDs causes a subsequent hydrolysis of ATP molecule that in turn leads to a conformational change in the shape of the transporter expelling the drug out of the cells (Hyde et al. 1990; Karthikeyan and Hoti 2015). This prohibits the intracellular accumulation of drugs from reaching their target, and eventually making chemotherapy ineffective. Natural chemosensitizers that proved to modulate the function of $\mathrm{ABCB} 1$ are listed in Tables 2 and 3.

\section{ABCC1 (MRP1)}

$\mathrm{ABCC} 1$ is a $190 \mathrm{kDa} \mathrm{ABC}$ transporter, which is expressed in liver, bowel, and excretory organs. It is also expressed in sanctuary sites such as the blood-brain barrier. Although the similarity between amino acid sequence of $\mathrm{ABCB} 1$ and $\mathrm{ABCC} 1$ is as low as $15 \%$, the resistance conferred through both proteins is significantly overlapping (Leschziner et al. 2006). As displayed in Fig. 3, the structure of $\mathrm{ABCC} 1$ is composed of three TMDs (TMD0, TMD1, and TMD2) and two cytoplasmic NBDs. Several chemotherapeutic agents such as doxorobicin, topotecan, and vincristine are substrates of $\mathrm{ABCC} 1$ in cancer cells (Kathawala et al. n.d.). However, $A B C C 1$ did not show efflux activity toward taxanes (i.e., paclitaxel as known ABCB1 substrate) (Morrow et al. 2006). Many modulators of $A B C B 1$ such as verapamil and cyclosporine $\mathrm{A}$ inhibit the function of $\mathrm{ABCC} 1$ as well (Zhou et al. 2008). Natural chemosensitizers that modulate the function of $\mathrm{ABCC} 1$ are listed in Tables 1 and 2 .

\section{ABCG2 (BCRP, MXR)}

ABCG2 is a $72 \mathrm{kDa} A B C$ half transporter and contains only one TMD and one NBD (Fig. 3) and only functions upon dimerization or by tetramer formation (Karthikeyan and Hoti 2015). This transporter was first identified and characterized in a MDR breast cancer cell line (MCF7) (Doyle et al. 1998). It is expressed normally in cells membranes of small intestine, placenta, brain, prostate, and ovaries. ABCG2 is also expressed in many types of cancer cells. Amphipathic molecules are substrates for ABCG2 transporter. This transporter also shares with other transporters the property of transporting structurally unrelated drugs. It can effectively efflux mitoxantrone and camptothecin as well as fluorescent dyes. Natural chemosensitizers that modulate the function of ABCG2 are listed in Tables 1 and 2.

\section{Generations of chemosensitizers}

Extensive research work has been performed to inhibit $A B C$ transporter function and expression to re-sensitize cancer cells to chemotherapy. Therefore, inhibitors (chemosensitizers) block the transporter to increase drug accumulation in MDR cancer cells, which results in a better cytotoxic effect by the corresponding chemotherapeutic drug (Wu et al. 2011). Three distinct generations of chemosensitizers have been classified according to the relative affinity, toxicity, and specificity (Palmeira et al. 2012).

\section{First-generation chemosensitizers}

Early attempts to screen for $\mathrm{ABC}$ transporter inhibitors employed already available drugs that are used in the clinic such as the calcium channel blockers verapamil (Tsuruo et al. 1981), immunosuppressive drugs such as cyclosporine A (Shiraga et al. 2001), and the antimalarial drug quinine (Karthikeyan and Hoti 2015; Krishna and Mayer 2001). However, the original pharmacological activity of these first-generation drugs (chemosensitizers) caused non-desirable toxicity to non-cancerous cells, were non-specific, and had low affinity to the $\mathrm{ABC}$ transporter so that they required high doses to function in vivo. Examples of first-generation chemosensitizers are displayed in Fig. 4.

\section{Second-generation chemosensitizers}

The limitations recorded with first-generation chemosensitizers led to subsequent attempts to chemically modify P-gp inhibitors and the second generation of chemosensitizers emerged. Examples are chemically modified analogues of first-generation chemosensitizers such as dexverapamil (verapamil's $R$-enantiomer) and PSC833 (valspodar, modified from cyclosporine A). Although second-generation chemosensitizers showed potent chemosensitization in MDR cancer cells in vitro, they displayed toxicity in animal models (Abdallah et al. 2015; Nawrath and Raschack 1987; Pirker et al. 1990). Furthermore, they caused drug-drug interaction in clinical trials, since they showed cytochrome P450 inhibitory activities (Klinkhammer et al. 2009). Examples of second-generation chemosensitizers are displayed in Fig. 5. 
<smiles>COc1ccc(CCN(C)CCCC(C#N)(c2ccc(OC)c(OC)c2)C(C)C)cc1OC</smiles>

Verapamil

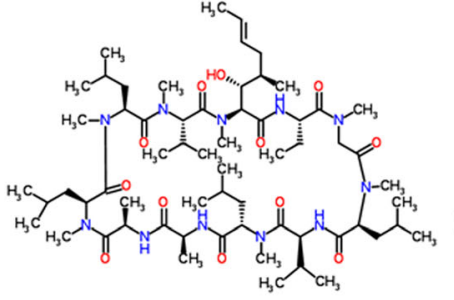

$\mathrm{H}_{3} \mathrm{C}^{-}$<smiles>C=C[C@H]1CN2CC[C@@H]1C[C@]2(CC)[C@H](O)c1ccnc2ccc(OC)cc12</smiles>

Cyclosporin A

Quinine

Fig. 4 Examples of first-generation chemosensitizers

\section{Third-generation chemosensitizers}

The advances in quantitative structure-activity relationship (QSAR) and combinatorial chemistry led to the emergence of the third-generation chemosensitizers with potent affinity to P-gp, less toxicity, and strong activity such as R1010933 (laniquidar), LY335979 (zosuquidar), GF120918 (elacridar), VX-710 (biricodar), and XR9576 (tariquidar) (Fig. 6). However, data from clinical trials revealed dual interactions with different types of $\mathrm{ABC}$ transporters (less selectivity to inhibit a given transporter) (Avendaño and Menéndez 2015; Toppmeyer et al. 2002; Yanagisawa et al. 1999).

\section{Mechanism of chemosensitization of MDR cells}

Avendano and co-workers (2015) summarized six possible mechanisms of actions of ABCB1/P-gp chemosensitizers (Fig. 7):
1. The chemosensitizer (e.g., verapamil) can be recognized as transporter substrate and lock the transporter in a cycle of transport and ATP hydrolysis, which in turn increases intracellular drug concentration.

2. Competitive inhibition by some chemosensitizers such as zosuquidar with longer and higher affinity to the drug binding site at the TMD of the transporter. Such compounds compete with the actual anticancer drug on the binding site of P-gp and block its transport.

3. Non-competitive inhibition of transporter by some chemosensitizers such as Cisflupenthixol that bind important amino acid residues on $\mathrm{P}$-gp sites other than the drug binding site (allosteric inhibition) and possibly interference with the conformation responsible for drug efflux.<smiles>COc1ccc(CCN(C)CCC[C@](C#N)(c2ccc(OC)c(OC)c2)C(C)C)cc1OC</smiles>

Dexverapam

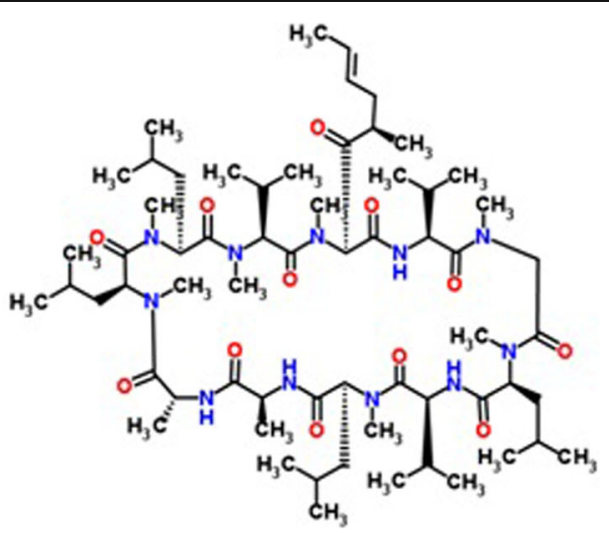

Pscasa

Fig. 5 Examples of second-generation chemosensitizers 


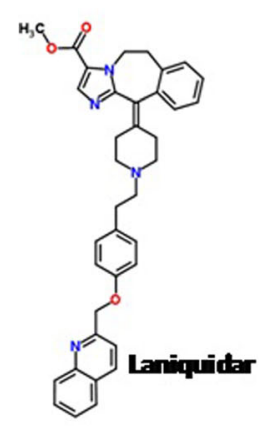<smiles></smiles><smiles></smiles><smiles>COc1cc(C(=O)C(=O)N2CCCCC2C(=O)OC(CCCc2cccnc2)CCCc2cccnc2)cc(OC)c1OC</smiles>

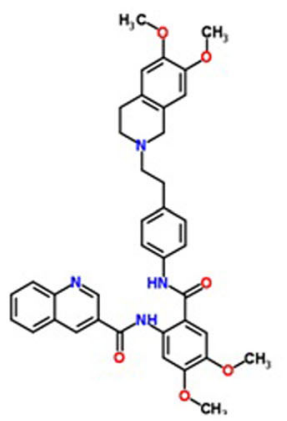

Bacridar

Biricodar

Taripuidar

Fig. 6 Examples of third-generation chemosensitizers



Fig. 7 Possible mechanisms of ABCB1/p-gp chemosensitizers. Adapted from (Avendaño and Menéndez 2015) under permission from Elsevier Inc 
Table 2 Examples of natural chemosensitizers of $A B C$ transporters isolated from plants

\begin{tabular}{|c|c|c|}
\hline Targeted ABC transporter & Chemosensitizer & Reference \\
\hline \multirow[t]{44}{*}{$\overline{A B C B 1 / P-g p / M D R-1}$} & 5-Bromotetrandrine & (Jin et al. 2005) \\
\hline & Abietane diterpene & (Madureira et al. 2004a) \\
\hline & Alisol B 23-acetate & (Wang et al. 2004a) \\
\hline & Amooranin & (Ramachandran et al. 2003) \\
\hline & Baicalein and derivatives & (Lee et al. 2004) \\
\hline & Biochanin A & (Zhang and Morris 2003) \\
\hline & Bitter melon extract & (Limtrakul et al. 2004) \\
\hline & Bufalin & (Mahringer et al. 2010) \\
\hline & Cannabinoids & (Zhu et al. 2006; Holland et al. 2006) \\
\hline & $\beta$-Carotene & (Teng et al. 2016) \\
\hline & Catechins & (Kitagawa et al. 2004) \\
\hline & Cepharanthine & (Koizumi et al. 1995) \\
\hline & Coumarins & (Raad et al. 2006) \\
\hline & Curcumin and semisynthetic derivatives & (Chearwae et al. 2004; Anuchapreeda et al. 2002; Ooko et al. 2016) \\
\hline & Cycloartanes & (Madureira et al. 2004b) \\
\hline & Deoxyschizandrin & (Yoo et al. 2007) \\
\hline & Didehydrostemofolines & (Umsumarng et al. 2017) \\
\hline & Eudesmin & (Lim et al. 2007) \\
\hline & Euphocharacins A-L & (Corea et al. 2004) \\
\hline & Ginkgo biloba extract & (Nabekura et al. 2008; Fan et al. 2009) \\
\hline & Ginsenoside Rg & (Kim et al. 2003) \\
\hline & Grapefruit juice extracts & (de Castro et al. 2007) \\
\hline & Hapalosin & (Palomo et al. 2004) \\
\hline & Hypericin and hyperforin & (Wang et al. 2004b) \\
\hline & Isoquinoline alkaloid, isotetrandrine & (Wang and Yang 2008) \\
\hline & Isostemofoline & (Umsumarng et al. 2017) \\
\hline & Jatrophanes & (Hohmann et al. 2003; Reis et al. 2016) \\
\hline & Kaempferia parviflora extracts & (Patanasethanont et al. 2007a) \\
\hline & Kavalactones & (Weiss et al. 2005) \\
\hline & Morin & (Zhang and Morris 2003) \\
\hline & Ningalin B and derivatives & (Soenen et al. 2003; Tao et al. 2004) \\
\hline & Opiates & (Hemauer et al. 2009) \\
\hline & Phloretin & (Zhang and Morris 2003) \\
\hline & Piperine & (Han et al. 2008) \\
\hline & Polyoxypregnanes & (KKW et al. 2017) \\
\hline & Protopanaxatriol ginsenosides & (Choi et al. 2003) \\
\hline & Pyranocoumarins & (Wu et al. 2003) \\
\hline & Quercetin & (Limtrakul et al. 2005; Scambia et al. 1994) \\
\hline & Schisandrol A & (Fong et al. 2007) \\
\hline & Sesquiterpenes & (Munoz-Martinez et al. 2004) \\
\hline & Silymarin & (Zhang and Morris 2003) \\
\hline & Sinensetin & (Choi et al. 2002) \\
\hline & Stemona curtisii root extract & (Limtrakul et al. 2007a) \\
\hline & Taxane derivatives & (Brooks et al. 2004; Zhao et al. 2004) \\
\hline
\end{tabular}


Table 2 Examples of natural chemosensitizers of $A B C$ transporters isolated from plants (Continued)

\begin{tabular}{|c|c|c|}
\hline Targeted ABC transporter & Chemosensitizer & Reference \\
\hline & Terpenoids & (Yoshida et al. 2006) \\
\hline & Tetrandine & (Fu et al. 2004) \\
\hline & Vitamin E TPGS & (Collnot et al. 2007) \\
\hline \multirow[t]{24}{*}{ ABCG2/BCRP/MXR } & 3'-4'-7-Trimethoxyflavone & (Katayama et al. 2007) \\
\hline & 6-Prenylchrysin & (Ahmed-Belkacem et al. 2005) \\
\hline & Acacetin & (Imai et al. 2004) \\
\hline & Biochanin A & (Zhang et al. 2004) \\
\hline & Cannabinoids & (Holland et al. 2007) \\
\hline & Chrysin & (Zhang et al. 2004) \\
\hline & Curcumin & (Chearwae et al. 2006a) \\
\hline & Daizein & (Cooray et al. 2004) \\
\hline & Eupatin & (Henrich et al. 2006) \\
\hline & Genistein & (Imai et al. 2004) \\
\hline & Ginsenosides & (Jin et al. 2006) \\
\hline & Harmine & (Ma and Wink 2010) \\
\hline & Hesperetin & (Cooray et al. 2004) \\
\hline & Kaempferol & (Imai et al. 2004) \\
\hline & Naringenin & (Imai et al. 2004) \\
\hline & Plumbagin & (Shukla et al. 2007) \\
\hline & Quercetin & (Cooray et al. 2004) \\
\hline & Resveratrol & (Cooray et al. 2004) \\
\hline & Rotenoids & (Ahmed-Belkacem et al. 2007) \\
\hline & Silymarin & (Cooray et al. 2004) \\
\hline & Stilbenoids & (Morita et al. 2005) \\
\hline & Tectochrysin & (Ahmed-Belkacem et al. 2005) \\
\hline & Terpenoids & (Yoshida et al. 2008) \\
\hline & Tetrahydrocurcumin & (Limtrakul et al. 2007b) \\
\hline \multirow[t]{8}{*}{ ABCC1/MRP1 } & Cannabinoids & (Holland et al. 2008) \\
\hline & Cepharanthine & (Abe et al. 1995) \\
\hline & Curcumin & (Chearwae et al. 2006b) \\
\hline & Ginkgo biloba extract & (Nabekura et al. 2008) \\
\hline & Kaempferia parviflora extracts & (Patanasethanont et al. 2007b) \\
\hline & Myricetin & (van Zanden et al. 2005) \\
\hline & Quercetin & (Leslie et al. 2001; Wu et al. 2005) \\
\hline & Stemona curtisii root extract & (Limtrakul et al. 2007a) \\
\hline
\end{tabular}

4. Some surfactants, anesthetics, and fluidizers nonspecifically perturb membrane lipids and thereby increase the rates of drug uptake (Ferte 2000; Eytan 2005).

5. Some chemosensitizers interfere with the ATPbinding domain of the transporter. An example of this mechanism is the trapping of ADP by vanadate at the ATP binding site (Urbatsch et al. 1995).

6. Some chemosensitizers can interfere with the intracellular ABCB1-mediated drug sequestration in vesicular membrane (e.g., lysosomal sequestration (Yamagishi et al. 2013)) making the drug more available to its cellular targets.

\section{Natural products: the fourth-generation of MDR chemosensitizers}

The high biodiversity, good oral bioavailability, and relatively low intrinsic toxicity of natural products enabled the discovery of new chemical scaffolds for drug development. Due to the limitations encountered by three generations of 
Table 3 Examples of chemosensitizers of ABC transporters isolated from natural sources (marine organisms, insects, and fungi)

\begin{tabular}{llll}
\hline Target ABC transporter & Chemosensitizer & Source & Reference \\
\hline ABCB1 & Agosterol A and derivatives & Marine organisms & (Mitsuo et al. 2003; Aoki et al. 1999) \\
& Kendarimide A & (Aoki et al. 2004) \\
& Polyoxygenated steroids & & (Tanaka et al. 2002) \\
& Sipholane triterpenoid & & (Shi et al. 2007a; Jain et al. 2007) \\
& Cantharidin trepene & (Zheng et al. 2008) \\
& Tryprostatin A & Insect & (Woehlecke et al. 2003) \\
& Tryptanthrin & Fungus & (Yu et al. 2007) \\
ABCG2 & Fumitremorgin C & Fungus & (Rabindran et al. 2000; Robey et al. 2001)
\end{tabular}

chemosensitizers, natural products are attractive partners for the combination with chemotherapy to enhance their cancer cytotoxic effects and reverse MDR. Edible phytochemicals such as curcumin, quercetin, and kaempferol block ABCB1 function and reverse MDR in human cancer cell lines (Limtrakul et al. 2005). Furthermore, some naturally derived compounds such as trabectedin, cytarabine, and halaven are clinically useful based on their strong chemosensitizing properties (Huang 2007; Shi et al. 2007a; Abraham et al. 2010; Lopez and Martinez-Luis 2014).

Herein, natural compounds such as phytochemicals, marine, or fungal compounds were presented as chemosensitizers of MDR cancer cells (Tables 2 and 3). These natural product chemosensitizers belong to diverse chemical classes, such as flavonoids, coumarines, terpenoids, etc. Listed natural products target the three major transporters ABCB1, ABCC1, and ABCG2.

\section{Conclusion}

A major hurdle of successful cancer chemotherapy is MDR caused by ABC transporters. Extensive research has been carried out to identify chemosensitizers with high selectivity, high affinity, and low toxicity. Three generations of chemosensitizers that reverse MDR have emerged without satisfactory clinical success due to limitation of their toxicity, low affinity, and non-selectivity. Natural products may represent attractive alternatives to synthetic compounds for the development as chemosensitizers in combination with chemotherapeutic agents to enhance their efficacy in cancer cells.

\section{Abbreviations}

ABC: ATP binding cassette; BCRP: Breast cancer resistance protein; MDR: Multidrug resistance; MRP: MDR-related protein; MXR: Mitoxantrone resistance protein; NBD: Nucleotide binding domain; P-gp: P-glycoprotein; TMD: Transmembrane domain

\section{Acknowledgements}

The authors acknowledge Elsevier Inc. for giving the permission to re-use Figs. 1, 2, 3, and 7 from cited references.

\section{Funding}

No sources of funding to be declared.
Availability of data and materials

Not applicable.

Authors' contributions

All Authors have contributed in writing, reading, and approval of the final manuscript.

Ethics approval and consent to participate

Not applicable.

Consent for publication

Not applicable.

Competing interests

The authors declare that they have no competing interests.

\section{Publisher's Note}

Springer Nature remains neutral with regard to jurisdictional claims in published maps and institutional affiliations.

Received: 20 November 2018 Accepted: 3 January 2019

Published online: 22 January 2019

References

Abdallah HM et al (2015) P-glycoprotein inhibitors of natural origin as potential tumor chemo-sensitizers: a review. J Adv Res 6(1):45-62.

Abe T et al (1995) Chemosensitisation of spontaneous multidrug resistance by a 1,4-dihydropyridine analogue and verapamil in human glioma cell lines overexpressing MRP or MDR1. Br J Cancer 72(2):418-423.

Abraham I et al (2010) Marine sponge-derived sipholane triterpenoids reverse Pglycoprotein (ABCB1)-mediated multidrug resistance in cancer cells. Biochem Pharmacol 80(10):1497-1506.

Ahmed-Belkacem A et al (2005) Flavonoid structure-activity studies identify 6prenylchrysin and tectochrysin as potent and specific inhibitors of breast cancer resistance protein ABCG2. Cancer Res 65(11):4852-4860.

Ahmed-Belkacem A et al (2007) Nonprenylated rotenoids, a new class of potent breast cancer resistance protein inhibitors. J Med Chem 50(8):1933-1938.

Anuchapreeda S et al (2002) Modulation of P-glycoprotein expression and function by curcumin in multidrug-resistant human KB cells. Biochem Pharmacol 64(4):573-582.

Aoki $S$ et al (1999) Reversal of multidrug resistance in human carcinoma cell line by agosterols, marine spongean sterols. Tetrahedron 55(49):13965-13972.

Aoki S et al (2004) Kendarimide a, a novel peptide reversing P-glycoproteinmediated multidrug resistance in tumor cells, from a marine sponge of Haliclona sp. Tetrahedron 60(33):7053-7059.

Avendaño C, Menéndez JC (2015) Chapter 14 - drugs that modulate resistance to antitumor agents. In: Medicinal chemistry of anticancer drugs (second edition). Elsevier, Boston, pp 655-700.

Bernardes de Andrade Carli C, Quilles MB, Carlos IZ (2013) Chapter 16-natural products with activity against multidrug-resistant tumor cells A2 - Rai, Mahendra Kumar. In: Kon KV (ed) Fighting Multidrug Resistance with Herbal Extracts, Essential Oils and Their Components. Academic Press, San Diego, pp 237-244. 
Brooks TA et al (2004) Structure-activity analysis of taxane-based broad-spectrum multidrug resistance modulators. Anticancer Res 24(2a):409-415.

Callies O et al (2016) Optimization by molecular fine tuning of Dihydro-betaagarofuran sesquiterpenoids as reversers of P-glycoprotein-mediated multidrug resistance. J Med Chem 59(5):1880-1890.

Carlson RW, Sikic BI (1983) Continuous infusion or bolus injection in cancer chemotherapy. Ann Intern Med 99(6):823-833.

Chearwae W et al (2004) Biochemical mechanism of modulation of human Pglycoprotein (ABCB1) by curcumin I, II, and III purified from turmeric powder. Biochem Pharmacol 68(10):2043-2052.

Chearwae W et al (2006a) Modulation of the function of the multidrug resistance-linked ATP-binding cassette transporter ABCG2 by the cancer chemopreventive agent curcumin. Mol Cancer Ther 5(8):1995-2006.

Chearwae $W$ et al (2006b) Curcuminoids purified from turmeric powder modulate the function of human multidrug resistance protein 1 (ABCC1). Cancer Chemother Pharmacol 57(3):376-388

Choi CH, Kang G, Min YD (2003) Reversal of P-glycoprotein-mediated multidrug resistance by protopanaxatriol ginsenosides from Korean red ginseng. Planta Med 69(3):235-240.

Choi CH et al (2002) Reversal of P-glycoprotein-mediated multidrug resistance by 5,6,7,3',4'-pentamethoxyflavone (Sinensetin). Biochem Biophys Res Commun 295(4):832-840

Collnot EM et al (2007) Mechanism of inhibition of P-glycoprotein mediated efflux by vitamin E TPGS: influence on ATPase activity and membrane fluidity. Mol Pharm 4(3):465-474.

Cooray HC et al (2004) Interaction of the breast cancer resistance protein with plant polyphenols. Biochem Biophys Res Commun 317(1):269-275.

Corea G et al (2004) Structure-activity relationships for euphocharacins A-L, a new series of jatrophane diterpenes, as inhibitors of cancer cell Pglycoprotein. Planta Med 70(7):657-665.

de Castro W et al (2007) Grapefruit juice-drug interactions: grapefruit juice and its components inhibit P-glycoprotein (ABCB1) mediated transport of talinolol in Caco-2 cells. J Pharm Sci 96(10):2808-2817.

Dean M, Annilo T (2005) Evolution of the ATP-binding cassette (ABC) transporter superfamily in vertebrates. Annu Rev Genomics Hum Genet 6:123-142.

Doyle LA et al (1998) A multidrug resistance transporter from human MCF-7 breast cancer cells. Proc Natl Acad Sci U S A 95(26):15665-15670.

Eichhorn T, Efferth T (2012) P-glycoprotein and its inhibition in tumors by phytochemicals derived from Chinese herbs. J Ethnopharmacol 141(2): 557-570.

Eytan GD (2005) Mechanism of multidrug resistance in relation to passive membrane permeation. Biomed Pharmacother 59(3):90-97.

Fan L et al (2009) Effects of Ginkgo biloba extract ingestion on the pharmacokinetics of talinolol in healthy Chinese volunteers. Ann Pharmacother 43(5):944-949.

Ferte J (2000) Analysis of the tangled relationships between P-glycoproteinmediated multidrug resistance and the lipid phase of the cell membrane. Eur J Biochem 267(2):277-294.

Fong WF et al (2007) Schisandrol a from Schisandra chinensis reverses Pglycoprotein-mediated multidrug resistance by affecting Pgp-substrate complexes. Planta Med 73(3):212-220.

Fromm MF (2004) Importance of P-glycoprotein at blood-tissue barriers. Trends Pharmacol Sci 25(8):423-429.

Fu L et al (2004) Characterization of tetrandrine, a potent inhibitor of P-glycoproteinmediated multidrug resistance. Cancer Chemother Pharmacol 53(4):349-356.

Gillet J-P, Efferth T, Remacle J (2007) Chemotherapy-induced resistance by ATPbinding cassette transporter genes. Biochimica et Biophysica Acta (BBA) Rev Cancer 1775(2):237-262.

Glavinas $\mathrm{H}$ et al (2004) The role of ABC transporters in drug resistance, metabolism and toxicity. Curr Drug Deliv 1(1):27-42.

Gottesman MM (2002) Mechanisms of cancer drug resistance. Annu Rev Med 53: 615-627.

Gottesman MM, Ambudkar SV (2001) Overview: ABC transporters and human disease. J Bioenerg Biomembr 33(6):453-458

Gottesman MM, Fojo T, Bates SE (2002) Multidrug resistance in cancer: role of ATP-dependent transporters. Nat Rev Cancer 2(1):48-58.

Gottesman MM, Ling V (2006) The molecular basis of multidrug resistance in cancer: the early years of P-glycoprotein research. FEBS Lett 580(4):998-1009.

Han Y, Chin Tan TM, Lim LY (2008) In vitro and in vivo evaluation of the effects of piperine on P-gp function and expression. Toxicol Appl Pharmacol 230(3): 283-289.
Hemauer SJ et al (2009) Opiates inhibit paclitaxel uptake by P-glycoprotein in preparations of human placental inside-out vesicles. Biochem Pharmacol 78(9):1272-1278.

Henrich CJ et al (2006) A high-throughput cell-based assay for inhibitors of ABCG2 activity. J Biomol Screen 11(2):176-183.

Hohmann J et al (2003) Jatrophane diterpenoids from Euphorbia mongolica as modulators of the multidrug resistance of L5128 mouse lymphoma cells. J Nat Prod 66(7):976-979.

Holland ML, Allen JD, Arnold JC (2008) Interaction of plant cannabinoids with the multidrug transporter ABCC1 (MRP1). Eur J Pharmacol 591(1-3):128-131.

Holland ML et al (2006) The effects of cannabinoids on P-glycoprotein transport and expression in multidrug resistant cells. Biochem Pharmacol 71(8):1146-1154

Holland ML et al (2007) The multidrug transporter ABCG2 (BCRP) is inhibited by plant-derived cannabinoids. Br J Pharmacol 152(5):815-824.

Huang Y (2007) Pharmacogenetics/genomics of membrane transporters in cancer chemotherapy. Cancer Metastasis Rev 26(1):183-201.

Hyde SC et al (1990) Structural model of ATP-binding proteins associated with cystic fibrosis, multidrug resistance and bacterial transport. Nature 346(6282): 362-365.

Ifergan I et al (2004) Folate deprivation results in the loss of breast cancer resistance protein (BCRP/ABCG2) expression. A role for BCRP in cellular folate homeostasis. J Biol Chem 279(24):25527-25534.

Imai $Y$ et al (2004) Phytoestrogens/flavonoids reverse breast cancer resistance protein/ABCG2-mediated multidrug resistance. Cancer Res 64(12):4346-4352.

Jain $S$ et al (2007) Reversal of P-glycoprotein-mediated multidrug resistance by sipholane triterpenoids. J Nat Prod 70(6):928-931.

Jin J et al (2005) Reversal of multidrug resistance of cancer through inhibition of P-glycoprotein by 5-bromotetrandrine. Cancer Chemother Pharmacol 55(2): $179-188$.

Jin J et al (2006) Metabolites of ginsenosides as novel BCRP inhibitors. Biochem Biophys Res Commun 345(4):1308-1314.

Juliano RL, Ling V (1976) A surface glycoprotein modulating drug permeability in Chinese hamster ovary cell mutants. Biochim Biophys Acta 455(1):152-162.

Kadioglu $O$ et al (2016) Interactions of human P-glycoprotein transport substrates and inhibitors at the drug binding domain: functional and molecular docking analyses. Biochem Pharmacol 104(Supplement C):42-51.

Karthikeyan S, Hoti SL (2015) Development of fourth generation ABC inhibitors from natural products: a novel approach to overcome cancer multidrug resistance. Anti Cancer Agents Med Chem 15(5):605-615.

Katayama K et al (2007) Flavonoids inhibit breast cancer resistance proteinmediated drug resistance: transporter specificity and structure-activity relationship. Cancer Chemother Pharmacol 60(6):789-797.

Kathawala RJ et al (2015) The modulation of ABC transporter-mediated multidrug resistance in cancer: a review of the past decade. Drug Resist Updat 18:1-17.

Kim SW et al (2003) Reversal of P-glycoprotein-mediated multidrug resistance by ginsenoside Rg(3). Biochem Pharmacol 65(1):75-82.

Kitagawa S, Nabekura T, Kamiyama S (2004) Inhibition of P-glycoprotein function by tea catechins in KB-C2 cells. J Pharm Pharmacol 56(8):1001-1005.

KKW T et al (2017) Reversal of multidrug resistance by Marsdenia tenacissima and its main active ingredients polyoxypregnanes. J Ethnopharmacol 203(Supplement C):110-119.

Klinkhammer W et al (2009) Synthesis and biological evaluation of a small molecule library of 3rd generation multidrug resistance modulators. Bioorg Med Chem 17(6):2524-2535.

Koizumi S et al (1995) Flow cytometric functional analysis of multidrug resistance by Fluo-3: a comparison with rhodamine-123. Eur J Cancer $31 \mathrm{a}(10): 1682-1688$

Krishna R, Mayer LD (2000) Multidrug resistance (MDR) in cancer. Mechanisms, reversal using modulators of MDR and the role of MDR modulators in influencing the pharmacokinetics of anticancer drugs. Eur J Pharm Sci 11(4): 265-283.

Krishna R, Mayer LD (2001) Modulation of P-glycoprotein (PGP) mediated multidrug resistance (MDR) using chemosensitizers: recent advances in the design of selective MDR modulators. Curr Med Chem Anticancer Agents 1(2):163-174.

Kuete V, Efferth T (2015) African Flora has the potential to fight multidrug resistance of cancer. Biomed Res Int 2015:24.

Kyle $\mathrm{AH}$ et al (2007) Limited tissue penetration of taxanes: a mechanism for resistance in solid tumors. Clin Cancer Res 13(9):2804-2810.

Lee $Y$ et al (2004) Increased anti-P-glycoprotein activity of baicalein by alkylation on the A ring. J Med Chem 47(22):5555-5566. 
Leschziner $\mathrm{G}$ et al (2006) Exon sequencing and high resolution haplotype analysis of $A B C$ transporter genes implicated in drug resistance. Pharmacogenet Genomics 16(6):439-450.

Leslie EM et al (2001) Modulation of multidrug resistance protein 1 (MRP1/ $A B C(1)$ transport and atpase activities by interaction with dietary flavonoids. Mol Pharmacol 59(5):1171-1180.

Lim S et al (2007) Reversal of P-glycoprotein-mediated drug efflux by eudesmin from Haplophyllum perforatum and cytotoxicity pattern versus diphyllin, podophyllotoxin and etoposide. Planta Med 73(15):1563-1567.

Limtrakul P, Khantamat O, Pintha K (2004) Inhibition of P-glycoprotein activity and reversal of cancer multidrug resistance by Momordica charantia extract. Cancer Chemother Pharmacol 54(6):525-530.

Limtrakul P, Khantamat O, Pintha K (2005) Inhibition of P-glycoprotein function and expression by kaempferol and quercetin. J Chemother 17(1):86-95.

Limtrakul P et al (2007a) Effect of Stemona curtisii root extract on P-glycoprotein and MRP-1 function in multidrug-resistant cancer cells. Phytomedicine 14(6): 381-389.

Limtrakul $P$ et al (2007b) Modulation of function of three $A B C$ drug transporters, P-glycoprotein (ABCB1), mitoxantrone resistance protein (ABCG2) and multidrug resistance protein 1 ( $A B C C 1$ ) by tetrahydrocurcumin, a major metabolite of curcumin. Mol Cell Biochem 296(1-2):85-95.

Longley DB, Allen WL, Johnston PG (2006) Drug resistance, predictive markers and pharmacogenomics in colorectal cancer. Biochim Biophys Acta 1766(2): 184-196.

Loo TW, Clarke DM (2005) Recent progress in understanding the mechanism of P-glycoprotein-mediated drug efflux. J Membr Biol 206(3):173-185.

Lopez D, Martinez-Luis S (2014) Marine natural products with P-glycoprotein inhibitor properties. Mar Drugs 12(1):525-546.

Ma Y, Wink M (2010) The beta-carboline alkaloid harmine inhibits BCRP and can reverse resistance to the anticancer drugs mitoxantrone and camptothecin in breast cancer cells. Phytother Res 24(1):146-149.

Madureira AM et al (2004a) A new sesquiterpene-coumarin ether and a new abietane diterpene and their effects as inhibitors of P-glycoprotein. Planta Med 70(9):828-833.

Madureira AM et al (2004b) Effect of cycloartanes on reversal of multidrug resistance and apoptosis induction on mouse lymphoma cells. Anticance Res 24(2b):859-864

Mahringer A et al (2010) Inhibition of P-glycoprotein at the blood-brain barrier by phytochemicals derived from traditional Chinese medicine. Cancer Genomics Proteomics 7(4):191-205.

Marangolo M et al (2006) Dose and outcome: the hurdle of neutropenia (review). Oncol Rep 16(2):233-248.

Matsumoto $S$ et al (2011) Antiangiogenic agent sunitinib transiently increases tumor oxygenation and suppresses cycling hypoxia. Cancer Res 71(20):6350-6359.

Mbaveng AT, Kuete V, Efferth T (2017) Potential of central, eastern and Western Africa medicinal plants for cancer therapy: spotlight on resistant cells and molecular targets. Front Pharmacol 8:343.

Mitsuo $M$ et al (2003) Binding site(s) on P-glycoprotein for a newly synthesized photoaffinity analog of agosterol A. Oncol Res 14(1):39-48.

Morita $\mathrm{H}$ et al (2005) Antimitotic activity and reversal of breast cancer resistance protein-mediated drug resistance by stilbenoids from Bletilla striata. Bioorg Med Chem Lett 15(4):1051-1054.

Morrow CS et al (2006) Multidrug resistance protein 1 (MRP1, ABCC1) mediates resistance to mitoxantrone via glutathione-dependent drug efflux. Mol Pharmacol 69(4):1499-1505.

Munoz-Martinez F et al (2004) Celastraceae sesquiterpenes as a new class of modulators that bind specifically to human P-glycoprotein and reverse cellular multidrug resistance. Cancer Res 64(19):7130-7138.

Nabekura T et al (2008) Inhibition of P-glycoprotein and multidrug resistance protein 1 by dietary phytochemicals. Cancer Chemother Pharmacol 62(5): 867-873.

Nawrath H, Raschack M (1987) Effects of (-)-desmethoxyverapamil on heart and vascular smooth muscle. J Pharmacol Exp Ther 242(3):1090-1097.

Nie J et al (2016) Efficacy of traditional Chinese medicine in treating cancer. Biomed Rep 4(1):3-14.

Ooko E et al (2016) Modulation of P-glycoprotein activity by novel synthetic curcumin derivatives in sensitive and multidrug-resistant T-cell acute lymphoblastic leukemia cell lines. Toxicol Appl Pharmacol 305(Supplement C):216-233

Palmeira A et al (2012) Three decades of P-gp inhibitors: skimming through several generations and scaffolds. Curr Med Chem 19(13):1946-2025.
Palomo C et al (2004) A practical total synthesis of hapalosin, a 12-membered cyclic depsipeptide with multidrug resistance-reversing activity, by employing improved segment coupling and macrolactonization. J Org Chem 69(12):4126-4134.

Patanasethanont D et al (2007a) Effects of Kaempferia parviflora extracts and their flavone constituents on P-glycoprotein function. J Pharm Sci 96(1):223-233.

Patanasethanont D et al (2007b) Modulation of function of multidrug resistance associated-proteins by Kaempferia parviflora extracts and their components. Eur J Pharmacol 566(1-3):67-74.

Pirker $\mathrm{R}$ et al (1990) Reversal of multi-drug resistance in human KB cell lines by structural analogs of verapamil. Int J Cancer 45(5):916-919.

Quintieri L, Fantin M, Vizler C (2007) Identification of molecular determinants of tumor sensitivity and resistance to anticancer drugs. Adv Exp Med Biol 593:95-104.

Raad I et al (2006) Structure-activity relationship of natural and synthetic coumarins inhibiting the multidrug transporter P-glycoprotein. Bioorg Med Chem 14(20):6979-6987.

Rabindran SK et al (2000) Fumitremorgin C reverses multidrug resistance in cells transfected with the breast cancer resistance protein. Cancer Res 60(1):47-50.

Ramachandran C et al (2003) Novel plant triterpenoid drug amooranin overcomes multidrug resistance in human leukemia and colon carcinoma cell lines. Int J Cancer 105(6):784-789.

Reis MA et al (2016) Jatrophane diterpenes and cancer multidrug resistance ABCB1 efflux modulation and selective cell death induction. Phytomedicine 23(9):968-978.

Robey RW et al (2001) Overexpression of the ATP-binding cassette halftransporter, ABCG2 (Mxr/BCrp/ABCP1), in flavopiridol-resistant human breast cancer cells. Clin Cancer Res 7(1):145-152.

Saeed MEM et al (2016) Cytotoxicity of south-African medicinal plants towards sensitive and multidrug-resistant cancer cells. J Ethnopharmacol 186:209-223.

Saluja R et al (2016) Disease volume and distribution as drivers of treatment decisions in metastatic prostate cancer: from chemohormonal therapy to stereotactic ablative radiotherapy of oligometastases. Urol Oncol 34(5):225-232.

Saraswathy M, Gong S (2013) Different strategies to overcome multidrug resistance in cancer. Biotechnol Adv 31(8):1397-1407.

Scambia G et al (1994) Quercetin potentiates the effect of adriamycin in a multidrug-resistant MCF-7 human breast-cancer cell line: P-glycoprotein as a possible target. Cancer Chemother Pharmacol 34(6):459-464.

Shi Z et al (2007a) Sipholenol A, a marine-derived sipholane triterpene, potently reverses P-glycoprotein (ABCB1)-mediated multidrug resistance in cancer cells. Cancer Sci 98(9):1373-1380.

Shi Z et al (2007b) Overexpression of Survivin and XIAP in MDR cancer cells unrelated to P-glycoprotein. Oncol Rep 17(4):969-976.

Shiraga K et al (2001) Modulation of doxorubicin sensitivity by cyclosporine A in hepatocellular carcinoma cells and their doxorubicin-resistant sublines. J Gastroenterol Hepatol 16(4):460-466.

Shukla S et al (2007) The naphthoquinones, vitamin K3 and its structural analogue plumbagin, are substrates of the multidrug resistance linked ATP binding cassette drug transporter ABCG2. Mol Cancer Ther 6(12 Pt 1):3279-3286.

Sikic BI (2015) Chapter 47 - Natural and acquired resistance to cancer therapies A2. In: John M, Gray JW et al (eds) The molecular basis of cancer (fourth edition). Elsevier Inc, Philadelphia, pp 651-660:e4.

Society., A.C. Cancer Facts \& Figures 2016; Available from: http://www.cancer.org/ acs/groups/content/@research/documents/document/acspc-047079.pdf.

Soenen DR et al (2003) Multidrug resistance reversal activity of key ningalin analogues. Bioorg Med Chem Lett 13(10):1777-1781.

Tanaka J et al (2002) New polyoxygenated steroids exhibiting reversal of multidrug resistance from the gorgonian Isis hippuris. Tetrahedron 58(32): 6259-6266.

Tao H, Hwang I, Boger DL (2004) Multidrug resistance reversal activity of permethyl ningalin B amide derivatives. Bioorg Med Chem Lett 14(24):5979-5981.

Teng YN et al (2016) beta-carotene reverses multidrug resistant cancer cells by selectively modulating human P-glycoprotein function. Phytomedicine 23(3): 316-323.

Toppmeyer D et al (2002) Safety and efficacy of the multidrug resistance inhibitor Incel (biricodar; VX-710) in combination with paclitaxel for advanced breast cancer refractory to paclitaxel. Clin Cancer Res 8(3):670-678.

Torre LA et al (2015) Global cancer statistics, 2012. CA Cancer J Clin 65(2):87-108.

Tsuruo T et al (1981) Overcoming of vincristine resistance in P388 leukemia in vivo and in vitro through enhanced cytotoxicity of vincristine and vinblastine by verapamil. Cancer Res 41(5):1967-1972. 
Turk D et al (2009) Identification of compounds selectively killing multidrugresistant cancer cells. Cancer Res 69(21):8293-8301.

Umsumarng S et al (2017) Modulation of P-glycoprotein by Stemona alkaloids in human multidrug resistance leukemic cells and structural relationships. Phytomedicine 34(Supplement C):182-190.

Urbatsch IL et al (1995) P-glycoprotein is stably inhibited by vanadate-induced trapping of nucleotide at a single catalytic site. J Biol Chem 270(33):1938319390.

van Zanden JJ et al (2005) Reversal of in vitro cellular MRP1 and MRP2 mediated vincristine resistance by the flavonoid myricetin. Biochem Pharmacol 69(11): $1657-1665$

Vasiliou V, Vasiliou K, Nebert DW (2009) Human ATP-binding cassette (ABC) transporter family. Human Genomics 3(3):281-290.

Wang C et al (2004a) Reversal of P-glycoprotein-mediated multidrug resistance by Alisol B 23-acetate. Biochem Pharmacol 68(5):843-855.

Wang EJ, Barecki-Roach M, Johnson WW (2004b) Quantitative characterization of direct P-glycoprotein inhibition by St John's wort constituents hypericin and hyperforin. J Pharm Pharmacol 56(1):123-128.

Wang TX, Yang XH (2008) Reversal effect of isotetrandrine, an isoquinoline alkaloid extracted from Caulis Mahoniae, on P-glycoprotein-mediated doxorubicin-resistance in human breast cancer (MCF-7/DOX) cells. Yao Xue Xue Bao 43(5):461-466.

Weiss J et al (2005) Extracts and kavalactones of Piper methysticum G. Forst (kavakava) inhibit P-glycoprotein in vitro. Drug Metab Dispos 33(11):1580-1583.

Woehlecke $\mathrm{H}$ et al (2003) Reversal of breast cancer resistance protein-mediated drug resistance by tryprostatin A. Int J Cancer 107(5):721-728.

Wu CP, Ohnuma S, Ambudkar SV (2011) Discovering natural product modulators to overcome multidrug resistance in cancer chemotherapy. Curr Pharm Biotechnol 12(4):609-620

Wu CP et al (2005) Modulatory effects of plant phenols on human multidrugresistance proteins 1, 4 and 5 (ABCC1, 4 and 5). FEBS J 272(18):4725-4740

Wu JY et al (2003) Reversal of multidrug resistance in cancer cells by pyranocoumarins isolated from Radix Peucedani. Eur J Pharmacol 473(1):9-17.

Wu Q et al (2014) Multi-drug resistance in cancer chemotherapeutics: mechanisms and lab approaches. Cancer Lett 347(2):159-166.

Yamagishi T et al (2013) P-glycoprotein mediates drug resistance via a novel mechanism involving lysosomal sequestration. J Biol Chem 288(44):31761-31771.

Yan X-J et al (2014) Triterpenoids as reversal agents for anticancer drug resistance treatment. Drug Discov Today 19(4):482-488.

Yanagisawa T et al (1999) BIRICODAR (VX-710; Incel): an effective chemosensitizer in neuroblastoma. Br J Cancer 80(8):1190-1196.

Yoo HH et al (2007) Effects of Schisandra lignans on P-glycoprotein-mediated drug efflux in human intestinal Caco-2. Planta Med 73(5):444-450.

Yoshida N et al (2006) Inhibition of P-glycoprotein-mediated transport by terpenoids contained in herbal medicines and natural products. Food Chem Toxicol 44(12):2033-2039.

Yoshida N et al (2008) Inhibitory effects of terpenoids on multidrug resistanceassociated protein 2- and breast cancer resistance protein-mediated transport. Drug Metab Dispos 36(7):1206-1211.

Yu J et al (2016) Advances in plant-based inhibitors of P-glycoprotein. J Enzyme Inhib Med Chem 31(6):867-881.

Yu ST et al (2007) Tryptanthrin inhibits MDR1 and reverses doxorubicin resistance in breast cancer cells. Biochem Biophys Res Commun 358(1):79-84.

Zhang S, Morris ME (2003) Effects of the flavonoids biochanin A, morin, phloretin and silymarin on P-glycoprotein-mediated transport. J Pharmacol Exp Ther 304(3):1258-1267.

Zhang S, Yang X, Morris ME (2004) Flavonoids are inhibitors of breast cancer resistance protein (ABCG2)-mediated transport. Mol Pharmacol 65(5):12081216.

Zhao X et al (2004) Synthesis and biological evaluation of taxinine analogues as orally active multidrug resistance reversal agents in cancer. Bioorg Med Chem Lett 14(18):4767-4770.

Zheng LH et al (2008) Cantharidin reverses multidrug resistance of human hepatoma HepG2/ADM cells via down-regulation of P-glycoprotein expression. Cancer Lett 272(1):102-109.

Zhou SF et al (2008) Substrates and inhibitors of human multidrug resistance associated proteins and the implications in drug development. Curr Med Chem 15(20):1981-2039.

Zhu HJ et al (2006) Characterization of P-glycoprotein inhibition by major cannabinoids from marijuana. J Pharmacol Exp Ther 317(2):850-857.

\section{Submit your manuscript to a SpringerOpen ${ }^{\circ}$ journal and benefit from:}

- Convenient online submission

- Rigorous peer review

- Open access: articles freely available online

- High visibility within the field

- Retaining the copyright to your article

Submit your next manuscript at $\boldsymbol{\nabla}$ springeropen.com 